\title{
Hydrolysis catalyzed with a resin containing histidine groups
}

\author{
Wei-Hsiu Hung, Cho-Chun Hu, Chuen-Ying Liu * \\ Department of Chemistry, National Taiwan University, Taipai, Taiwan, ROC
}

Received 4 August 1995; accepted 19 October 1995

\begin{abstract}
A histidine-containing polymer was synthesized in which the amino group of the histidine was attached chemically via an azide coupling method to the carboxylic acid of Amberlite IRC-50. The resultant polymer was applied as a catalyst for hydrolysis of $p$-nitrophenyl acetate (PNPA). PNPA in aqueous solution was hydrolyzed at $25^{\circ} \mathrm{C}$ with a phosphate buffer $(\mathrm{pH}$ 7.8). The observed kinetics obeyed Michaelis-Menten kinetics. The reaction rates at various temperature were measured. The activation parameters, preexponential factor $(A)$ and activation energy $\left(E_{\mathrm{a}}\right)$, were $6.64 \times 10^{-4} \mathrm{~min}^{-1}$ and $37.5 \mathrm{~kJ}$ $\mathrm{mol}^{-1}$ respectively. At a $\mathrm{pH}$ of the medium greater than 7.8 , the reaction rate remained almost constant $\left(k_{\text {obs }}=0.024\right.$ $\min ^{-1}$ ) and seemed to be controlled by the rate of diffusion of PNPA from the bulk solution into the catalytically active site at the resin channel surface. For catalysed hydrolysis, the effect of ionic strength in solution demonstrated that bifunctional cooperation between adjacent histidine groups existed through the nucleophilicity of nitrogen. The effects of metal ions and aspartic acid or serine on hydrolysis were also investigated.
\end{abstract}

Keywords: Histidine-containing resin; Hydrolysis; p-Nitrophenyl acetate

\section{Introduction}

Enzyme models are not proteins; they have the advantage of being more stable and can thus be prepared by synthetic methods. Because the mechanism of action of hydrolytic enzymes such as $\alpha$-chymotrypsin was the first to be elucidated in detail, tests of enzyme models mostly involved the hydrolysis of phenyl esters. The imidazole group of the histidyl residue is involved in the catalytic action of many hydrolytic enzymes, and imidazole itself can act as a basic catalyst in various reactions. Therefore, in

\footnotetext{
* Corresponding author.
}

a typical catalytic-group approach, imidazole compounds are used widely as a hydrolytic enzyme model $[1,2]$.

Many reactions in aqueous surfactant solutions occur at the interface between micellar hydrocarbon and water. The adsorption of reactants at these micellar interfaces and their subsequent reactions resemble reactions controlled by enzymes. Large rate enhancements are observed because reactants are concentrated in the micellar pseudophase. Gitler and Solano used a nucleophile that contained the bulky alkyl group $N$-myristyl-L-histidine for the catalytic reaction of $p$-nitrophenyl esters [3]. Bunton and Ihara tested the catalytic activity of $N$-decanoylhistidine in the presence of comicellization with 
$\mathrm{CTABr}$ [4]. Ihara and Hosako investigated stereoselective reactions of enantiomers of $\mathrm{N}$ acylamino acid $p$-nitrophenyl esters with $N$-decanoyl-(D or $\mathrm{L}$ )-histidine in an optically active surfactant derived from (L)-ephedrine [5]. Chiral $p$-nitrophenyl esters derived from phenylalanine were cleaved with histidine-containing dipeptides at a micellar interface [6]. Ohkubo et al. found a peculiar enantioselective hydrolysis of $N$-acyl amino acid esters with L (or D)histidine-attached $\beta$-cyclodextrins [7] and in bilayer vesicular systems containing the tripeptide-type histidine derivative $Z$-L-Leu-L-His-LLeu [8].

We previously synthesized a histidine-containing resin to extract metal ions [9]. In the present work, we report the catalytic effects of histidine-containing polymers on hydrolysis of $p$-nitrophenyl acetate. Catalytic activities of polymer-supported catalysts are essentially smaller than those of the corresponding catalysts of small molar mass, but insoluble polymer catalysts are easily separated by filtration from the reactant or product at the end of a reaction and can be reused for further runs.

\section{Experimental}

\subsection{Apparatus}

Elemental analysis was performed on an elemental analyzer (Perkin Elmer 240C). IR spectra of a resin in $\mathrm{KBr}$ pellets were recorded on an infrared spectrophotometer (Perkin Elmer 983). A UV-vis spectrophotometer (Hitachi U-3200) was used for absorbance measurements. A pH meter (Radiometer, Copenhagen, Denmark, PHM 61) was used to measure the $\mathrm{pH}$ of a solution.

\subsection{Chemicals}

Most chemicals were of analytical reagent grade (E. Merck, Darmstadt, Germany). p-
Nitrophenylacetate (PNPA) (Aldrich, Milwaukee, WI, USA) was purified from ethyl acetate. Pure water $(18 \mathrm{M} \Omega \cdot \mathrm{cm})$ from a water purification system (Milli-Q Ultrapure Water System, Millipore, USA) was used to prepare all solutions. The stock solutions (ca. $0.1 \mathrm{M}$ ) of metal ions were prepared on dissolving an appropriate amount of the respective metal salt in nitric acid $(0.1 \mathrm{M})$, diluting with pure water (to $250 \mathrm{ml}$ ), adjusting to $\mathrm{pH} 1.6$, and storing in polyethylene bottles. The concentration of metal ion was verified on EDTA complexometric titration.

\subsection{Synthesis of histidine-containing resin}

The histidine-containing resin was prepared as described previously [9]. To the pretreated Amberlite IRC-50 resin $(6 \mathrm{~g})$ placed in a flask containing methanol $(600 \mathrm{ml})$, sulfuric acid (18 $\mathrm{M}, 1.5 \mathrm{ml}$ ) as catalyst was added dropwise. The resultant mixture was refluxed at $70^{\circ} \mathrm{C}$ for $20 \mathrm{~h}$. The product was cooled to room temperature and collected by filtration under suction and washed sequentially with water and methanol until no sulfate ion appeared in the filtrate. The procedures were repeated to obtain a higher yield. Then hydrazine $(3 \mathrm{ml})$ was added dropwise to product 1 and reacted at room temperature for $30 \mathrm{~h}$. The product was washed with water until no hydrazine appeared in the filtrate. To product 2 was added hydrochloric acid ( 0.5 $\mathrm{M}, 50 \mathrm{ml}$ ). While the mixture was constantly agitated in a freezing mixture of salt and ice, a solution of sodium nitrite $(0.2 \mathrm{M}, 10 \mathrm{ml})$ was added dropwise. After the addition was complete, the mixture was stirred at $0^{\circ} \mathrm{C}$ for $30 \mathrm{~min}$, and histidine $(4 \mathrm{~g})$ was added. In this process, triethylamine $\left(0^{\circ} \mathrm{C}, 50 \mathrm{ml}\right)$ was added to adjust the $\mathrm{pH}$ to $8.0-8.5$. The reaction mixture was stirred and kept at $0^{\circ} \mathrm{C}$ for $48 \mathrm{~h}$. Then ammonia-ammonium chloride ( $1 \mathrm{M}, 5 \mathrm{ml})$ was added to remove the unreacted azide. The final product was collected on suction filtration and washed sequentially with hydrochloric acid (0.1 $\mathrm{M})$, water and methanol to remove unreacted starting material. 


\subsection{Potentiometric titrations}

\subsubsection{Acid dissociation constant}

In this investigation, at least 14 samples of the resin $(0.2 \mathrm{~g})$ were accurately weighed and placed respectively in each PE bottle $(100 \mathrm{ml})$. Aqueous solutions containing various amounts of sodium hydroxide $(0.1 \mathrm{M})$ were made to ionic strength $(0.1 \mathrm{M})$ with potassium chloride and brought to a total volume $(25 \mathrm{ml})$. The solutions were added to a $\mathrm{PE}$ bottle containing the resin. The mixture was stirred for $4 \mathrm{~h}$ at $(25 \pm 0.1)^{\circ} \mathrm{C}$. After equilibration, the $\mathrm{pH}$ was measured.

\subsection{Kinetic of hydrolysis of p-nitrophenyl ac- etate}

The reactions were carried out by measuring the absorbance of $p$-nitrophenol with a spectrophotometer, a thermostated cell compartment and a thermostated ccll holder. The reaction medium, potassium chloride $(0.068 \mathrm{M}, 145 \mathrm{ml})$ and phosphate buffer $(0.014 \mathrm{M})$ of varied $\mathrm{pH}$ in dioxane aqueous solution $(2: 3, \mathrm{v} / \mathrm{v})$ was placed in an apparatus under nitrogen and thermostatted at $(25 \pm 0.1)^{\circ} \mathrm{C}$ for $30 \mathrm{~min}$. The reaction was initiated on the addition of a stock solution ( 2 $\left.\mathrm{ml}, 5.35 \times 10^{-3} \mathrm{M}\right)$ of the ester in acetonitrile.

\section{Results and discussion}

The histidine-containing resin (PHis) was prepared and characterized in accordance with the previously reported method [9]. The procedures are shown as Scheme 1 . The $\mathrm{p} K_{\mathrm{a}}$ value of the protonated imidazolium group of the resin determined according to potentiometric titration is 5.80. Bjerrum's method was applied to the system according to a detailed procedure [10]. Scheme 2 shows the apparatus for the catalytic system. We chose $p$-nitrophenyl acetate (PNPA) as the model compound.

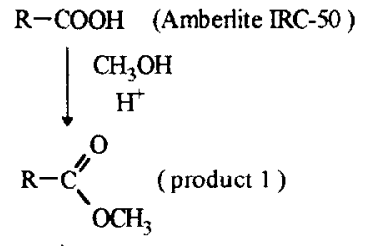
$\mid \begin{aligned} & \mathrm{NH}_{2} \mathrm{NH}_{3} \mathrm{OH} \\ & \text { root temp. }\end{aligned}$<smiles>[R]C(=O)NN</smiles><smiles>[R]C(N)=O</smiles><smiles>CCCCc1ncc(CC(N)C(=O)O)[nH]1</smiles><smiles>[R]C(=O)NC(Cc1cnc[nH]1)C(=O)O</smiles>

Scheme 1. Synthesis of histidine-containing resin

In the presence of a catalytic species, the coefficient of the rate of reaction is,

$k_{\text {obs }}=k_{\mathrm{w}}+k_{\mathrm{cat}}$

in which $k_{\mathrm{w}}$ is the kinetic coefficient for the spontaneous reaction and $k_{\text {cat }}$ for the catalytic reaction. By varying the amount of resin, the rate coefficients, $k_{\text {obs }}$, were obtained by plotting In $A_{\infty} /\left(A_{\infty}-A_{\mathrm{t}}\right)$ vs. time (Fig. 1). Only under the condition ln $A_{\infty} /\left(A_{\infty}-A_{t}\right)<0.3$ did a linear relationship exist, such that $k_{\text {obs }}$ is constant; at greater values of $\ln A_{\infty} /\left(A_{\infty}-A_{\mathrm{t}}\right)$, a curvature appeared. The initial rate of production of $p$-nitrophenol increases with increasing temperature. Catalysis is demonstrated when the rate of 


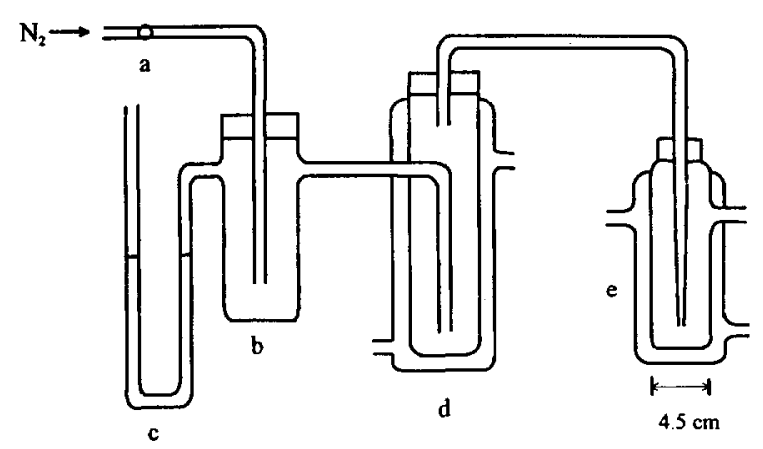

Scheme 2. The apparatus for the catalytic system. a. Pressure gauge; b. trap; c. manometer; d. thermostat flask; e. reactor.

hydrolysis is greater in the presence of the potential catalyst than in its absence. Observed coefficients for the rate of hydrolysis increased from $4.3 \times 10^{-4} \mathrm{~min}^{-1}$ with no catalyst to a maximum $2.2 \times 10^{-2} \mathrm{~min}^{-1}$ at $0.1 \mathrm{~g}$ of PHis per $147 \mathrm{ml}$ of PNPA (Table 1). Acetamide or Amberlite IRC-50 resin gave no significant enhancement of the hydrolysis. Only histidine and histidine resin catalysed the hydrolysis. The rate was most enhanced for the histidine-containing resin among all materials tested. At a constant PNPA concentration, the rate increased linearly with the weight of resin, whereas at a constant

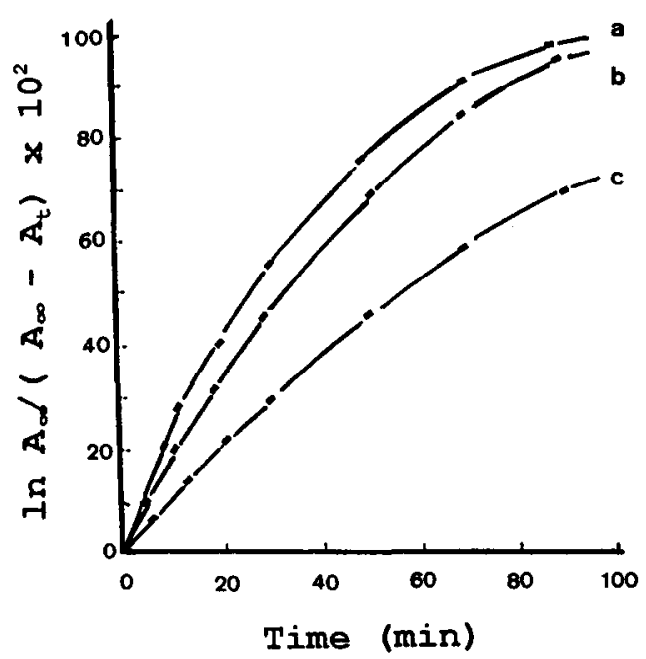

Fig. 1. Plot of $\ln A_{\infty} /\left(A_{\infty}-A_{\mathrm{t}}\right)$ vs. time for deacylation of PNPA. Phosphate buffer $(0.014 \mathrm{M}, \mathrm{pH} 7.5)-\mathrm{KCl}(0.068 \mathrm{M})$ mixture in dioxane aqueous solution $(2: 3, \mathrm{v} / \mathrm{v})$, at $25^{\circ} \mathrm{C}$. Weight of PHis: a. $0.15 \mathrm{~g}$; b. $0.10 \mathrm{~g}$; c. $0.05 \mathrm{~g}$. Volume of solution: 147 $\mathrm{ml}$.
Table 1

Rates of cleavage of PNPA with various catalysts

\begin{tabular}{lcc}
\hline Catalyst & Concentration & $\begin{array}{c}k_{\text {obs }}{ }^{2} / 10^{-4} \\
\mathrm{~min}^{-1}\end{array}$ \\
\hline Spontaneous hydrolysis & & 4.3 \\
Acetamide & $5.0 \times 10^{-3} \mathrm{M}$ & 4.3 \\
Amberlite IRC-50 & $0.1 \mathrm{~g} / 147 \mathrm{ml}$ & 3.9 \\
Histidine (His) $^{\text {Histidine resin (PHis) }}{ }^{\mathrm{b}}$ & $3.2 \times 10^{-3} \mathrm{M}$ & 95 \\
\hline
\end{tabular}

${ }^{a}$ Phosphate buffer $(\mathrm{pH} 7.5,0.014 \mathrm{M})-\mathrm{KCl}(0.068 \mathrm{M})$ mixture in dioxane aqueous solution $(2: 3, v / v)$, at $25^{\circ} \mathrm{C}$.

${ }^{b}$ Bead size: $60-100 \mathrm{mesh}$; water regain: $49 \mathrm{mmol}^{-1}$; nitrogen content: $1.59 \mathrm{mmol} \mathrm{g}^{-1}$; hydrogen capacity: $1.42 \mathrm{mmol} \mathrm{g}^{-1} ; \mathrm{p} K_{\mathrm{a}}$ of imidazolium group: 5.80 .

amount of resin, the rate is proportional to the amount of PNPA at a concentration less than $3 \times 10^{-4} \mathrm{M}$ until it levels to a plateau at the concentration greater than $3 \times 10^{-4} \mathrm{M}$ (Fig. 2). These phenomena indicate saturated binding of catalyst to substrate and that the mechanism obeys the Michaelis-Menten equation, in which $V_{s}$, the maximum reaction velocity, is $4.02 \times$ $10^{-4} \mathrm{M} \mathrm{min}^{-1}$, and $k_{\mathrm{s}}$, the Michaelis parameter, is $1.68 \times 10^{-2} \mathrm{M}$. At this stage, the catalyst is completely acylated and the rate is indepen-

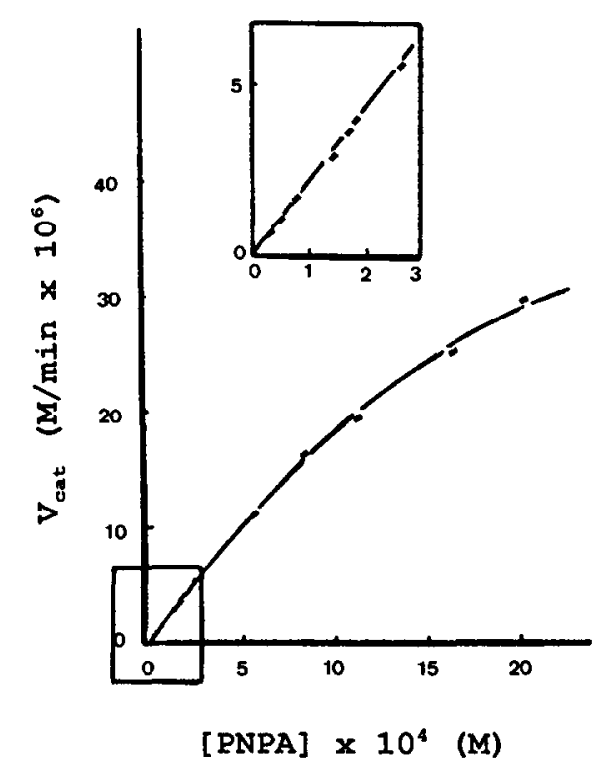

Fig. 2. Dependence of $k_{\text {obs }}$ on PNPA concentration. Phosphate buffer $(0.014 \mathrm{M}, \mathrm{pH} 7.5)-\mathrm{KCl}(0.068 \mathrm{M})$ mixture, at $25^{\circ} \mathrm{C}$. Amount of PHis: $0.10 \mathrm{~g}$. Volume of solution: $147 \mathrm{ml}$. 
dent of the substrate concentration. Hydrolysis of PNPA by both histidine (His) and histidinecontaining resin (PHis) possesses a significantly profile of rate with $\mathrm{pH}$ (Fig. 3). At small $\mathrm{pH}$, the reaction with PHis was lower than that with His, but as the media became more basic, a sharply increased reaction rate and gradual saturation at $\mathrm{pH}$ greater than 7.8 for $\mathrm{PHis}$ were observed. Although neutral and anionic forms of imidazole are present in greater fractions in both His and $\mathrm{PHis}$ at larger $\mathrm{pH}$, which act as the catalytic sites, another force might be exhibited by Phis for the mentioned property. The effect of temperature on the catalytic activity of His and PHis at varied $\mathrm{pH}$ toward PNPA is shown

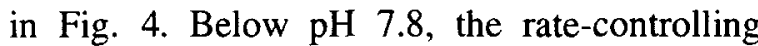
step for PHis with activation energy $E_{\mathrm{a}}=37.5$ $\mathrm{kJ} \mathrm{mol}^{-1}$ and pre-exponential factor $A=8.64$ $\times 10^{4} \mathrm{~min}^{-1}$, might be attributed to a pseudohomogeneous system like that for the monomeric histidine catalyst. The $E_{\mathrm{a}}$ for the monomeric histidine is $45.2 \mathrm{~kJ} \mathrm{~mol}^{-1}$ and $A$ is $7.67 \times 10^{5} \mathrm{~min}^{-1}$. At $\mathrm{pH}$ above 7.8 , that $E_{\mathrm{a}}$ for PHis is $34.7 \mathrm{~kJ} \mathrm{~mol}^{-1}$ might be attributed to diffusion control by the resin matrix [1]. That

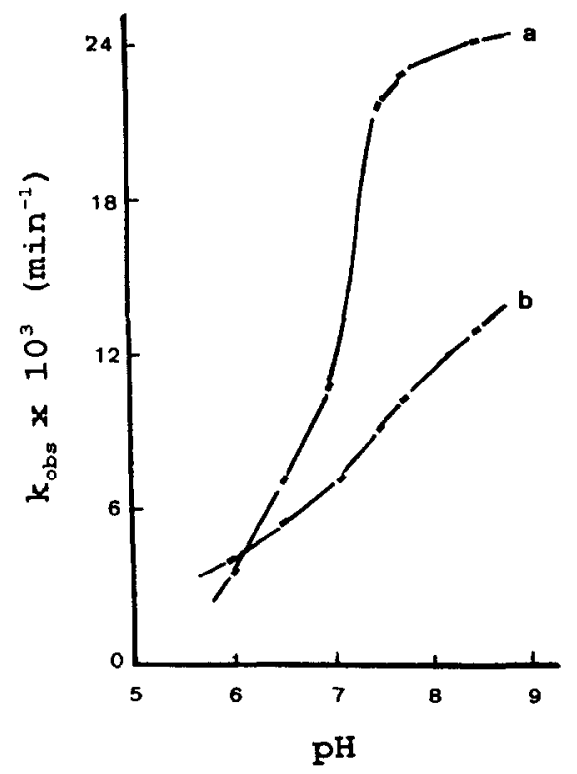

Fig. 3. Rate vs. pH for deacylation of PNPA. Conditions as Fig. 1. a. Amount of PHis: $0.1 \mathrm{~g}$; b. $[\mathrm{His}]=3.24 \times 10^{-3} \mathrm{M}$.

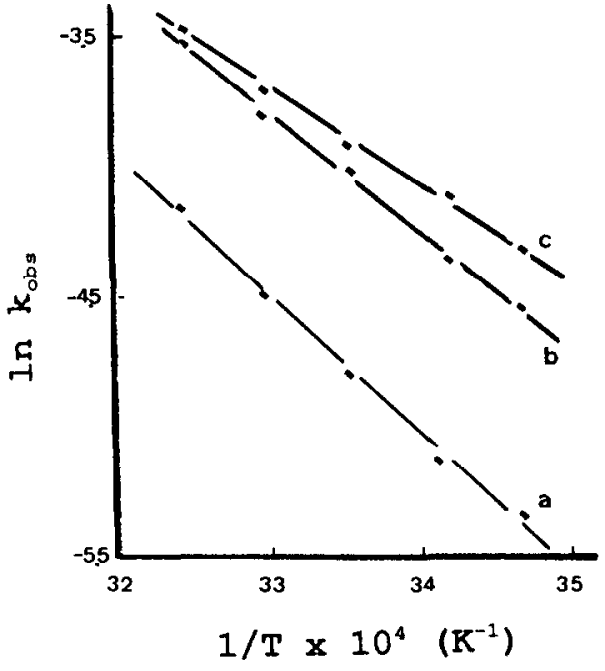

Fig. 4. Effect of temperature on deacylation of PNPA.Conditions as for Fig. 1, except c. at pH 8.0. a. [His]: $3.24 \times 10^{-3} \mathrm{M}$; b, c. Amount of PHis: $0.1 \mathrm{~g}$.

the activation energy for the histidine-containing resin is smaller than for monomeric histidine indicates that bifunctional groups interact in the resin to offer an easier mechanism for the catalysis [11]. Additionally, this distinction may indicate that deacylation is assisted by the binding force of the polymer chain. That the preexponential factor for the resin is smaller than that of monomeric histidine might be due to steric hindrance of the resin matrix. In considering the salt effect upon hydrolysis of PNPA, we find the catalytic behavior of histidine to be similar to that commonly found in catalytic reactions [12], but different from that of histidine-containing resin (Table 2). Lee and Ford found a similar phenomenon in that added chloride ion depressed the rate of hydrolysis by displacing $o$-iodosobenzoate from latex [13]. For reactions in various solvents, the less polar is the solvent, the slower is the reaction (Table 2). As there is a certain quantity of variation in the solvent regain, the catalytic condition chosen is under $\mathrm{pH} 8.5$, for which the rate of reaction is predominantly controlled by diffusion. The rate decreases in the order $\mathrm{H}_{2} \mathrm{O}>\mathrm{CH}_{3} \mathrm{OH}>$ $\mathrm{C}_{2} \mathrm{H}_{5} \mathrm{OH}>1,4$ dioxane. The results also indicate that $\mathrm{His}$ is less affected by the polarity of 
Table 2

Solvent and salt effects for hydrolysis of PNPA ${ }^{a}$

\begin{tabular}{|c|c|c|c|}
\hline \multirow[t]{2}{*}{ Solvent } & \multirow{2}{*}{$\begin{array}{l}\text { Solvent } \\
\text { regain / } \\
\mathrm{mlg}^{-1}\end{array}$} & \multicolumn{2}{|c|}{$k_{\mathrm{obs}} / 10^{-3} \mathrm{~min}^{-1}$} \\
\hline & & His & PHis \\
\hline $\mathrm{H}_{2} \mathrm{O}$ & 0.878 & 9 & 25 \\
\hline $\mathrm{H}_{2} \mathrm{O}^{\mathrm{b}}$ & & 10 & 22 \\
\hline $\mathrm{H}_{2} \mathrm{O}^{\mathrm{c}}$ & & 10 & 19 \\
\hline $\mathrm{H}_{2} \mathrm{O}^{d}$ & & 11 & 14 \\
\hline $\mathrm{H}_{2} \mathrm{O}^{\mathrm{e}}$ & & & 24 \\
\hline $\mathrm{CH}_{3} \mathrm{OH} / \mathrm{H}_{2} \mathrm{O}^{e . f}$ & 0.856 & 4 & 12 \\
\hline $\mathrm{C}_{2} \mathrm{H}_{5} \mathrm{OH} / \mathrm{H}_{2} \mathrm{O}^{\text {e,f }}$ & 0.791 & & 10 \\
\hline Dioxane $/ \mathrm{H}_{2} \mathrm{O}^{\mathrm{eff}}$ & 0.505 & & 5 \\
\hline
\end{tabular}

${ }^{a}$ Phosphate buffer $(\mathrm{pH} 7.5,0.014 \mathrm{M})-\mathrm{KCl}(0.034 \mathrm{M})$, at $25^{\circ} \mathrm{C}$ [His]: $3.24 \times 10^{-3} \mathrm{M}$; amount of resin: $0.1 \mathrm{~g}$; volume of solution: $147 \mathrm{ml}$.

${ }^{b}$ Conditions as in footnote a, except $[\mathrm{KCl}]: 0.068 \mathrm{M}$.

${ }^{c}$ Conditions as in footnote a, except [KCl]: $0.170 \mathrm{M}$.

${ }^{d}$ Conditions as in footnote a, except [KCl]: $0.340 \mathrm{M}$.

${ }^{\mathrm{e}}$ Conditions as in footnote b, except phosphatc buffer at pH 8.5

f Solvent ratio: $2 / 3$ by $\mathrm{v} / \mathrm{v}$.

the solvent than PHis (Fig. 5). According to these properties, bifunctional cooperation between adjacent histidine groups for the resin might exist through the nucleophilicity of nitrogen in a more polar solvent. Bifunctional cooperation became less important in the less polar solvent. By comparing the catalytic activity of

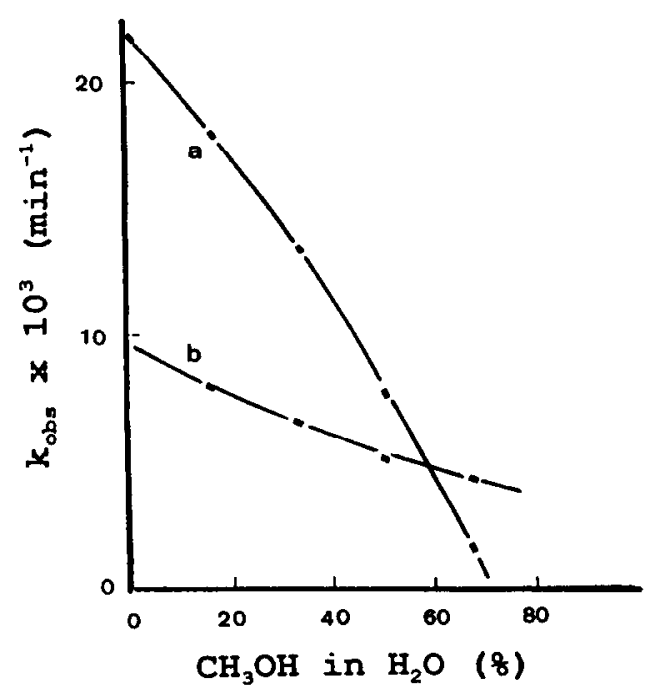

Fig. 5. Variation of reaction rate with composition of solvent. Conditions as for Fig. 1. a. Amount of PHis: $0.1 \mathrm{~g}$; b. [His]: $3.24 \times 10^{-3} \mathrm{M}$.
Table 3

Effect of metal ions on hydrolysis of PNPA

\begin{tabular}{lll}
\hline $\begin{array}{l}\text { Metal ion } \\
\text { concentration } \\
10^{-5} \mathrm{M}\end{array}$ & \begin{tabular}{l}
$k_{\mathrm{obs}}{ }^{\mathrm{a}}$ \\
\cline { 2 - 3 } $\mathrm{His}^{\mathrm{b}} / 10^{-3}$ \\
$\mathrm{~min}^{-1}$
\end{tabular} & $\begin{array}{l}\mathrm{PHis}^{\mathrm{c}} / 10^{-2} \\
\mathrm{~min}^{-1}\end{array}$ \\
\hline $\begin{array}{l}\text { Control } \\
\mathrm{Cu}(I I)\end{array}$ & 9.51 & 2.18 \\
1.53 & & \\
2.96 & 9.02 & 1.93 \\
6.62 & 8.25 & 1.70 \\
$N i(I I)$ & 5.94 & 1.05 \\
1.61 & & \\
3.12 & 8.59 & 2.28 \\
6.61 & 6.70 & 2.18 \\
$\mathrm{Zn}(I I)$ & 5.33 & 1.99 \\
1.73 & & \\
3.34 & 9.13 & 2.53 \\
7.09 & 8.79 & 1.90 \\
\hline
\end{tabular}

${ }^{\mathrm{a}}$ Phosphate buffer ( $\left.\mathrm{pH} 7.5,0.014 \mathrm{M}\right)-\mathrm{KCl}(0.068 \mathrm{M})$ mixture in dioxane aqueous solution $(2: 3, v / v)$, at $25^{\circ} \mathrm{C}$.

[ [His]: $3.24 \times 10^{-3} \mathrm{M}$.

c Amount of resin: $0.1 \mathrm{~g}$; volume of solution: $147 \mathrm{ml}$.

the monomeric functional group with the polymer-supported catalyst with the same functional group, we can improve the explanation of the mechanism.

The presence of metal ion in the catalytic system was also tested (Table 3). Although zinc seems required for the catalysis, at higher concentrations it inhibited the hydrolysis. Copper and nickel ions are not effective reactivators, perhaps because the chelate formation toward the histidine functional groups might be followed by a conformational change or blockage of the active site of the catalyst. Carboxypeptidase A, among the first metalloenzymes to be discovered, extensively investigated by kinetic, structural and spectral methods. There is no direct coordination of the carbonyl oxygen to $\mathrm{Zn}^{2+}$ before addition of water. The role of $\mathrm{Zn}^{2+}$ is therefore to stabilize negatively charged intermediates formed during hydrolysis rather than to polarize a bound carbonyl $[14,15]$. In view of catalytic properties of zinc ion in the metalloenzyme, the above results seem rational. In order to assess the deacylation of PNPA, we also examined the effect of aspartic acid and serine (Table 4), as histidine, serine and aspartic 
Table 4

Effect of aspartic acid and serine upon deacylation

\begin{tabular}{|c|c|c|}
\hline & $k_{\text {obs }}{ }^{a} / 1$ & ${ }^{-3} \min ^{-1}$ \\
\hline & Control & PHis $(0.1 \mathrm{~g} / 147 \mathrm{ml})$ \\
\hline Control & 0.43 & 21.8 \\
\hline Aspartic acid and serine ${ }^{b}$ & 0.40 & 19.1 \\
\hline
\end{tabular}

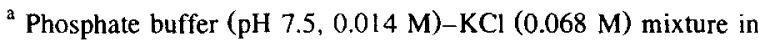
dioxane aqueous solution $(2: 3, v / v)$, at $25^{\circ} \mathrm{C}$.

${ }^{\mathrm{b}}[$ Aspartic acid $]=[$ Serine $]=8.9 \times 10^{-4} \mathrm{M}$.

acid involve the active site of the hydrolytic enzyme. They insignificantly affected the reaction rate. These phenomena indicate a less favorable fit of the substrate and the catalytic environment in the transition structure.

\section{Conclusion}

In dioxane-aqueous solution the histidine moiety in the resin is an active site in the hydrolysis of $p$-nitrophenyl acetate. Upon increasing the substrate concentration, typical Michaelis-Menten kinetics is observed. The polymer matrix provides a hydrophobic force for catalytic binding, and adjacent functional groups in the resin play an important role of bifunctional interaction in the catalytic process. Zinc ion at the optimum concentration stabilizes the transition structure.

Although it is impossible to prove an enzyme mechanism based on simple model experiments, detailed mechanistic tests on simple enzyme models can provide some information insight into how enzymes work. In addition, the cata- lyst will be highly promising in organic synthesis, pharmaceutical use and food chemistry.

\section{Acknowledgements}

We thank the National Science Council of the Republic of China for financial support.

\section{References}

[1] T. Kunitake, Enzyme-like Catalysis by Synthetic Linear Polymers, in P. Hodge and D.C. Sherrington (Eds.), Polymer-Supported Reactions in Organic Synthesis, John Wiley and Sons, Chichester, 1980.

[2] J. Chin, M. Banaszczyk, V. Jubian, J.H. Kim and K. Mrejen, Artificial Hydrolytic Metalloenzymes, in H. Dugas (Ed.), Bioorganic Chemistry Frontiers, Vol. 2, Springer-Verlag, Berlin, 1991

[3] C. Gitler, A. Ochoa-Solano. J. Am. Chem. Soc.. 90 (1968) 5004.

[4] C.A. Bunton, Y. Ihara, J. Org. Chem., 42 (1977) 2865.

[5] Y. Ihara, R. Hosako, Bull. Chem. Soc. Jpn., 55 (1982) 1979.

[6] M.C. Cleij, W. Drenth and R.J.M. Nolte, J. Org. Chem., 56, (1991) 3883

[7] K. Ohkubo, H. Ishida, K. Yamaki and M. Kawata, Chem. Lett., (1991) 1723.

[8] K. Ohkubo, Y. Nakano and H. Nagamura, J. Mol. Catal., 28 (1985) 1.

[9] C.Y. Liu, Anal. Chim. Acta, 192 (1987) 85.

[10] C.Y. Liu, M.J. Chen, N.M. Lee, H.C. Hwang, S.T. Jou and J.C. Hsu, Polyhedron, 11, (1992) 551.

[11] R. Breslow, Pure Appl. Chem., 66 (1994) 1573.

[12] M.L. Bender and B.W. Turnquest, J. Am. Chem. Soc., 79 (1957) 1052.

[13] J.J. Lee and W.T. Ford, J. Am. Chem. Soc., 116 (1994) 3753.

[14] E.T. Kaiser and B.L. Kaiser, Acc. Chem. Res., 5, (1992) 219.

[15] D.W. Christianson and W.N. Lipscomb, Acc. Chem. Res., 22 (1989) 62. 